American Journal of Agricultural and Biological Sciences 9 (3): 394-400, 2014

ISSN: $1557-4989$

(C) 2014 F. Sgroi et al., This open access article is distributed under a Creative Commons Attribution

(CC-BY) 3.0 license

doi:10.3844/ajabssp.2014.394.400 Published Online 9 (3) 2014 (http://www.thescipub.com/ajabs.toc)

\title{
STRATEGY TO INCREASE THE FARM COMPETITIVENESS
}

\author{
Filippo Sgroi, Anna Maria Di Trapani, Riccardo Testa and Salvatore Tudisca
}

Department of Agricultural and Forestry Sciences, University of Palermo, Italy

Received 2014-05-21; Revised 2014-06-09; Accepted 2014-06-14

\begin{abstract}
Italy's wine-growing production structure is highly pulverized. So, for many wine-growing farms lowering the production cost represents the only way of gaining a competitive advantage. Production at average unit costs lower than competitors allows to improve profitability. Among farming operations, winter pruning and tying of productive vine-branches require a high human labor. For this reason the paper presents the results of research conducted on a sample of Sicilian wine-producing farms in order to study the cost-effectiveness to make the pruning and the subsequent ligation of productive branches with tools that facilitate the work. The economic analysis, after the determination of minimum optimum size, shows that the investment is suitable for both large or small farms. This denotes how the process innovation could represent a way to achieve a cost leadership and improve profit margin.
\end{abstract}

Keywords: Break-Even Point, Competitiveness, Costs, Farms, Profitability

\section{INTRODUCTION}

As highlighted by statistics, Italy's wine-growing production structure is highly pulverized. According the latest available data (ISTAT, 2014), Sicily in 2011 with 106,092 hectares and a production of 700,581 tons, is first Italian Region in terms of wine grape area (16.5\% of the national wine grapes area), thanks to its favorable climate (Grillone et al., 2014; 2012; 2009; Ibáñez et al., 2014; D'Asaro and Grillone, 2012; Agnese et al., 2008) and the fourth for harvested production $(11.6 \%$ of the Italian wine grapes production). Over the last decade there has been a decline both in terms of wine grape area $(-11.2 \%)$ and harvested production $(-13.5 \%)$. In Sicily there are $10.4 \%$ of Italian winegrowing farms $(40,629$ units), with an average farm size amounting to 0.35 ha (ISTAT, 2012). The distribution of Sicilian productive structures according to wine grape area shows that $41.4 \%$ of farms have a size less than one hectare, while those less than 5 hectares account for $85 \%$ of the total. For these micro-enterprises, that produce an undifferentiated product, lowering the total cost of production per unit to a level below that of the Corresponding Author: Filippo Sgroi, Department of Agricultural and Forestry Sciences, University of Palermo, Italy competition represents the only way of gaining a competitive advantage (Tudisca et al., 2013a; Barber, 2012). Indeed, assuming no difference in sales price of grapes, production at average unit costs lower than the competition allows businesses to improve profitability and to obtain a higher sustainability with lower riskmanagement (Dittmar, 2014; El Dabee et al., 2013; Zhou and Lu, 2012; Santeramo et al., 2012). This situation affects the financial structure and the investment capacity of the undertakings. Moreover, increased net margins allow businesses to improve the ability to self-finance and, consequently, the remuneration of the factors of production (Tudisca et al., 2014a). An increase in financing sources may, in any case, give impetus to growth, possibly allowing businesses to affirm themselves on the market in the long term by offering new products that differ from their competitors, thereby creating differential advantage (Tudisca et al., 2013b; Rodriguez et al., 2002).

In wine-grape growing enterprises, one of the cultural operations amenable to measures aimed at reducing production costs is winter pruning (Kostadinov et al., 2008). This operation, together with the tying of 94 
productive vine-branches, represents a particular burden, given that it is distinctly demanding in terms of its labor requirements (Pezzi et al., 2013; Rolshausen et al., 2010; Smithyman et al., 1997). Nowadays the mechanical engineering sector offers wine growers a variety of power tools and machinery, allowing them to significantly curb time requirements for operations, thereby reducing production costs (Dokoozlian, 2013; Tardaguila et al., 2012; Gotyal et al., 2010; Morris, 2007; Intrieri and Poni, 2000).

This study is geared towards analyzing the modifications of production costs in wine-grape growing enterprises, whose business structures avail themselves of power-assisted pruning shears and tying tools. Their purchase does not entail prohibitive cost expenditures and the investment is, therefore, well within the capacities of the vast majority of agricultural enterprises. However, before embarking on the investment the wine grower must know its convenience and the relative cost-benefit ratio. Accordingly, an ex-ante assessment of the investment was performed in order to estimate its economic feasibility, by comparing the pruning costs and the subsequent ligation of productive branches according to two different modalities: Manual and powerassisted. Subsequently it has been determined the minimum optimum size that justify the introduction of power-assisted pruning and tying in farms.

\section{MATERIALS AND METHODS}

In vineyards trained in the counter-espalier system, pruning practices, besides the removal of unproductive canes, also involve trimming of vine shoots and tying fruiting canes to trellising wires. The economic analysis, aiming to identify the minimum optimum size (or breakeven point) of the agricultural enterprise that allows the investment, was conducted in Sicily considering data taken from several case studies on wine-growing undertakings in the province of Trapani. The enterprises on which the empirical studies were conducted mirror most of those of the territory, both in terms of management modalities, as well as in their business orientation (Lanfranchi et al., 2014; Tudisca et al., 2014b; 2011; Salami et al., 2010). The cultivated grape varieties examined were: Nero d'Avola, Merlot, Syrah and Chardonnay, trained in the counter-espalier system with a density of about 5,000 plants/ha also adopting a Guyot pruning system.
The study was conducted by comparing the pruning and the subsequent ligation of productive branches costs according to two different modalities:

- Pruning with manual hand shears and subsequent tying of fruiting canes (manual pruning)

- Pruning and tying of fruiting canes utilizing electric shears and tying tools, respectively (power-assisted pruning)

All items of cost incurred by wine growers for the pruning task under both procedural modalities (manual and power-assisted) were considered. The total pruning cost is the sum of the fixed and variable costs (Tudisca et al., 2014c; Guerrieri et al., 1995). Included among fixed costs are capital asset depreciation and the eventual interest costs incurred in acquiring these assets. Variable costs, instead, are those represented by maintenance, electrical energy, labor, purchase of string or PVC tubing for tying, as well as the interest on agricultural loans for operating credit needs (Fiala and Bacinetti, 2012; Landa, 2012; Othman and Manan, 2011). The total unit cost is calculated as the sum of the fixed costs, per hectare of vineyard subjected to the intervention and the variable costs for each hectare likewise subjected (Keskin et al., 2010; Çetin and Vardar, 2008). Subsequently an estimate of the minimum break-even surface that makes the cost of manual pruning equal to the power-assisted option has been determined (Selvan et al., 2012; Bao et al., 2010; Gunnarsson et al., 2009). By comparing the fixed and variable costs of the two pruning hypotheses the breakeven point may be found, i.e., the vineyard surface area whereby hypothesis a is equal to hypothesis $b$.

The break-even point can be determined using the following equation:

$$
\begin{aligned}
& \frac{C f_{a}}{x}+C v_{a}=\frac{C f_{b}}{x}+C v_{b} \\
& x=\frac{C f_{a}-C f_{b}}{C v_{b}-C v_{a}}
\end{aligned}
$$

Where:

$C f_{a}=$ Annual fixed costs hypothesis a

$C f_{b}=$ Annual fixed costs hypothesis $\mathrm{b}$

$C v_{a}=$ Variable costs per hectare of vineyard surface area hypothesis a

$C b_{b}=$ Variable costs per hectare of vineyard surface area hypothesis $b$

$x=$ Break-even point (hectares of vineyard surface area) 
Filippo Sgroi et al. / American Journal of Agricultural and Biological Sciences 9 (3): 394-400, 2014

Table 1. Technical-economic features of the used tools

\begin{tabular}{lccc}
\hline Items & Electric shears & Electric tying tools & Normal handheld shears \\
\hline Purchase price $(€)$ & $1,400.00$ & 900.00 & 20.00 \\
Annual usage (hours) & 500.00 & 500.00 & 500.00 \\
Economic life cycle $(y)$ & 8.00 & 5.00 & 3.00 \\
\hline
\end{tabular}

Source: Our processing of directly collected data

Table 1 shows the technical-economic features of the tools used for vineyard pruning tasks.

\section{RESULTS}

The costs of pruning and tying operations are distinguished between the two study hypotheses considered (Table 2 and 3 ).

In particular, in the case of Nero d'Avola the total unit cost amounts to 1,046.33 Euro/ha (hypothesis a) against 1,127.62 Euro/ha (hypothesis b). For the Merlot cultivated grape variety the figures are 1,087.20 Euro/ha against 1,149.21 Euro/ha, respectively. In the case of the Syrah variety the results are 1,129.22 Euro/ha and 1,239.39 Euro/ha. Finally, the Chardonnay variety produced values equal to 950.88 Euro/ha and $1,113.59$ Euro/ha, respectively.

The total unit costs of hypothesis a decrease minimally with increasing hectares of surface under vine, most of them being represented by variable costs which remain unchanged for each hectare of vineyard undergoing pruning and tying operations. The total unit costs of hypothesis b, however, register an appreciable reduction with increasing vineyard surface undergoing pruning. In the latter case, contrary to hypothesis a (amounting to 7.07 Euro), the fixed costs actually assume a distinct significance in function of the expenditure for the investment, amounting to 401.00 Euro, by the entrepreneur. For the four cultivated grape varieties examined the break-even points resulted to be equal to: 1.26 hectares for Nero d'Avola; 1.32 hectares for Merlot; 1.38 hectares for Syrah and 1.44 hectares for Chardonnay. In the latter case, the minimum optimal acreage is greater than in the other grape varieties, due to the lower workload required.

In light of these results, calculations were made to quantify the actual reduction in pruning costs due to the lessened labor time, hence lower relative cost. Switching from hypothesis $a$ to $b$ in the case of surfaces under vine equal to the optimal minimum size determined, allows to cut labor costs by $32.0 \%$ for
Nero d'Avola, 30.6\% for Merlot, 27.6\% for Syrah and by $29.3 \%$ for Chardonnay. The greater the vineyard surface area on which pruning tasks are performed, the more convenient hypothesis $b$, rather than $a$. In fact, in enterprises with a surface under vine of 5 hectares, the reduction in total cost, for pruning and tying, by cultivated grape variety equals $28.6 \%$ for Nero d'Avola, 26.9\% for Merlot, 23.9\% for Syrah, while Chardonnay exhibits a somewhat more limited reduction of $26.6 \%$ (Table 4 ).

\section{DISCUSSION}

The comparison of the two hypotheses shows a reduction of total unit cost in power-assisted pruning respect to manual one in all detected grape cultivar, as well as in other studies (Kaan Kurtural et al., 2012; Bates and Morris, 2009).

From the perspective afforded by the study hypothesis, the differences between the four grape varieties considered may be ascribed to the fact that the workload required to prune the three red grape varieties was more labor-intensive than for the Chardonnay, inasmuch as the plant density did not vary (Chinnici et al., 2013).

The study conducted also highlighted the fact that the investment to assist the vineyard tasks of pruning and tying is warranted for wine-growing undertakings adopting a Guyot pruning system, even for those inferior to 2 hectares. In this way, also small companies could introduce process innovations and obtain a competitive advantage in the international wine market (Tudisca et al., 2013c; Clingeleffer, 2013; Ghani et al., 2013). So, considering the difficulties that farms have to be competitive (high production costs, low sales prices of agricultural products, lack of human labor), the process innovation could represent a way to achieve a cost leadership and improve profit margin (Cerutti et al., 2014; Tudisca et al., 2014d; Houssou et al., 2013; Rahman and Takeda, 2007). 
Table 2. Costs in manual pruning and tying hypothesis according to cultivated grape variety

\begin{tabular}{|c|c|c|c|c|c|c|c|c|}
\hline \multirow[b]{3}{*}{ Costs } & \multicolumn{8}{|c|}{ Cultivated grape variety } \\
\hline & \multicolumn{2}{|c|}{ Nero d'Avola } & \multicolumn{2}{|l|}{ Merlot } & \multicolumn{2}{|l|}{ Syrah } & \multicolumn{2}{|c|}{ Chardonnay } \\
\hline & Pruning & Tying & Pruning & Tying & Pruning & Tying & Pruning & Tying \\
\hline \multicolumn{9}{|l|}{ Fixed costs: } \\
\hline Depreciation & 6.67 & - & 6.67 & - & 6.67 & - & 6.67 & - \\
\hline Interest & 0.40 & - & 0.40 & - & 0.40 & - & 0.40 & - \\
\hline Total fixed costs (Euro/y) & 7.07 & - & 7.07 & - & 7.07 & - & 7.07 & - \\
\hline \multicolumn{9}{|l|}{ Variable costs: } \\
\hline Maintenance & 0.01 & - & 0.01 & - & 0.01 & - & 0.01 & - \\
\hline Labor & 10.22 & 10.22 & 10.22 & 10.22 & 10.22 & 10.22 & 10.22 & 10.22 \\
\hline Tubing & - & 0.55 & - & 0.51 & - & 0.58 & - & 0.50 \\
\hline $\begin{array}{l}\text { Interest for agricultural } \\
\text { operating credit }\end{array}$ & 0.26 & 0.27 & 0.26 & 0.27 & 0.26 & 0.27 & 0.26 & 0.27 \\
\hline Total variable costs (Euro/hour) & 10.49 & 11.04 & 10.49 & 11.00 & 10.49 & 11.07 & 10.49 & 10.99 \\
\hline Total variable costs (Euro/ha) & 597.69 & 441.57 & 660.60 & 384.94 & 702.55 & 420.66 & 524.29 & 461.50 \\
\hline Total unit cost TUC (Euro/ha) & 604.76 & 441.57 & 667.67 & 384.94 & 709.62 & 419.60 & 531.36 & 395.57 \\
\hline
\end{tabular}

Source: Our processing of directly collected data

Table 3. Costs in power-assisted pruning and tying hypothesis according to cultivated grape variety

\begin{tabular}{|c|c|c|c|c|c|c|c|c|}
\hline \multirow[b]{3}{*}{ Costs } & \multicolumn{8}{|c|}{ Cultivated grape variety } \\
\hline & \multicolumn{2}{|c|}{ Nero d'Avola } & \multicolumn{2}{|l|}{ Merlot } & \multicolumn{2}{|l|}{ Syrah } & \multicolumn{2}{|c|}{ Chardonnay } \\
\hline & Pruning & Tying & Pruning & Tying & Pruning & Tying & Pruning & Tying \\
\hline \multicolumn{9}{|l|}{ Fixed Costs: } \\
\hline Depreciation & 175.00 & 180.00 & 175.00 & 180.00 & 175.00 & 180.00 & 175.00 & 180.00 \\
\hline Interest & 28.00 & 18.00 & 28.00 & 18.00 & 28.00 & 18.00 & 28.00 & 18.00 \\
\hline Total fixed costs (Euro/y) & 203.00 & 198.00 & 203.00 & 198.00 & 203.00 & 198.00 & 203.00 & 198.00 \\
\hline \multicolumn{9}{|l|}{ Variable costs: } \\
\hline Maintenance & 0.18 & 0.06 & 0.18 & 0.06 & 0.18 & 0.06 & 0.18 & 0.06 \\
\hline Electrical energy & 0.01 & 0.01 & 0.01 & 0.01 & 0.01 & 0.01 & 0.01 & 0.01 \\
\hline Labor & 10.22 & 10.22 & 10.22 & 10.22 & 10.22 & 10.22 & 10.22 & 10.22 \\
\hline String & - & 0.96 & - & 1.04 & - & 1.15 & - & 0.76 \\
\hline $\begin{array}{l}\text { Interest for agricultural } \\
\text { operating credit }\end{array}$ & 0.26 & 0.28 & 0.26 & 0.28 & 0.26 & 0.29 & 0.26 & 0.28 \\
\hline Total variable costs (Euro/hour) & 10.67 & 11.53 & 10.67 & 11.61 & 10.67 & 11.73 & 10.67 & 11.33 \\
\hline Total variable costs (Euro/ha) & 426.81 & 299.81 & 469.49 & 278.72 & 533.51 & 304.88 & 384.13 & 328.46 \\
\hline Total unit cost TUC (Euro/ha) & 629.81 & 497.81 & 672.49 & 476.72 & 736.51 & 502.88 & 587.13 & 526.46 \\
\hline
\end{tabular}

Source: Our processing of directly collected data

Table 4. Total costs for wine-growing enterprises with a vine surface of 5 ha (euro)

\begin{tabular}{|c|c|c|c|c|}
\hline \multirow[b]{2}{*}{ Hypothesis } & \multicolumn{4}{|c|}{ Cultivated grape variety } \\
\hline & Nero d'Avola & Merlot & Syrah & Chardonnay \\
\hline a) Manual pruning and tying & $5,197.71$ & $5,229.11$ & $5,617.46$ & $4,930.36$ \\
\hline b) Power-assisted pruning and tying & $3,713.30$ & $3,821.25$ & $4,272.15$ & $3,643.15$ \\
\hline Variation $\% \mathrm{~b} / \mathrm{a}$ & -28.60 & -26.90 & -23.90 & -26.10 \\
\hline
\end{tabular}




\section{CONCLUSION}

In wine growing, as in many branches of agriculture, the capacity to contain production costs represents an indispensable choice for the enterprise. Lowering mean costs allows a business to arrive to market with a lower price (albeit above mean cost) than the competition, who are destined to lose market shares to the competitor able to produce at more convenient costs. The exploitation of economies of scale together with expertise allow businesses, successful in lowering total unit costs, to embark on a process of growth that, in the medium/long term, may lead to an economic/productive leadership status in its sector, as well as from a supply chain perspective. Such a condition, other than accruing a competitive edge for the business itself, may promote local development, attract investments, generate revenues and employment.

The modest prices of grapes registered by small- and medium-sized enterprises that do no more than produce wine grapes, combined with the pronounced pulverization of enterprises determine the current crisis of the compartment. Those measures able to influence pruning costs, as demonstrated in this study, by way of tools that facilitate vineyard tasks, represent a viable path for large wine-growing undertakings, but above all for small- and medium-sized wine-growing enterprises that make up the overwhelming majority of Italian and Sicilian wine-growing productive structures.

So, it appears evident how the wine-growing farms have to invest in process innovation to remain competitive in an increasing globalized market, where competitors are able to decrease quickly their production costs.

\section{ACKNOWLEDGEMENT}

This study is a result of the full collaboration of all the authors. However, R. Testa wrote paragraph 1, F. Sgroi elaborated paragraph 2, A.M. Di Trapani wrote paragraphs 3 and 4, while S. Tudisca elaborated paragraph 5.

\section{REFERENCES}

Agnese, C., F. D'Asaro, G. Grillone and A. Drago, 2008. Comparison of temperature data collected in urban and agricultural areas surrounding. Italian $\mathbf{J}$. Agrometeorol., 13: 48-49.

Bao, B., M.M. El-Halwagi and N.O. Elbashir, 2010. Simulation, integration and economic analysis of gas-to-liquid processes. Fuel Process. Technol., 91: 703-713. DOI: 10.1016/j.fuproc.2010.02.001
Barber, W.L., 2012. Orchards of the future and implications for mechanical harvesting. Acta Horticulturae, 965: 113-116.

Bates, T. and J. Morris, 2009. Mechanical cane pruning and crop adjustment decreases labor costs and maintains fruit quality in New York 'concord' grape production. Hort Technol., 19: 247-253.

Cerutti, A.K., A. Calvo and S. Brun, 2014. Comparison of the environmental performance of light mechanization and animal traction using a modular LCA approach. J. Cleaner Product., 64: 396-403. DOI: 10.1016/j.jclepro.2013.09.027

Çetin, B. and A. Vardar, 2008. An economic analysis of energy requirements and input costs for tomato production in Turkey. Renewable Energy, 33: 428433. DOI: 10.1016/j.renene.2007.03.008

Chinnici, G., B. Pecorino, M. Rizzo and P. Rapisarda, 2013. Evaluation of the performances of wine producers in Sicily. Quality-Access Success, 14: 108-113.

Clingeleffer, P.R., 2013. Mechanization in Australian vineyard. Acta Horticolturae, 978: 169-177.

D'Asaro, F. and G. Grillone, 2012. Empirical investigation of curve number method parameters in the Medi-terranean area. J. Hydrol. Eng. 17: 1141-1152. DOI: 10.1061/(ASCE)HE.1943-5584.0000570.

Dittmar, M., 2014. Development towards sustainability: How to judge past and proposed polices. Sci. Total Environ., $\quad 472$ : 282-288. DOI: $10.1016 /$ j.scitotenv.2013.11.020

Dokoozlian, N., 2013. The evolution of mechanized vineyard production systems in California. Acta Horticulturae, 978: 265-278.

El Dabee, F., R. Marian and Y. Amer, 2013. A novel optimization model for simultaneous cost-risk reduction in multi-suppliers just-in-time systems. J. Comput. Sci., 9: 1778-1792. DOI: 10.3844/jcssp.2013.1778.1792

Fiala, M. and J. Bacinetti, 2012. Economic, energetic and environmental impact in short rotation coppice harvesting operations. Biomass Bioenergy, 42: $107-$ 113. DOI: 10.1016/j.biombioe.2011.07.004

Ghani, M.N.A., R.M. Hudzari, F.I.A. Wahab, M.R.H. Ramli and A.W.M. Azhar et al., 2013. Design, construction and evaluation of a smart agricultural harvester. Adv. Mater. Res., 705: 487-492. DOI: 10.4028/www.scientific.net/AMR.705.487

Gotyal, S.H., J.G. Angadi, S.G. Aski, M.B. Patil and S.S. Dolli et al., 2010. Constraints and suggestions of grape growers for improvement in grape production and marketing. Inter. J. Agric. Stat. Sci., 6: 293-298. 
Grillone, G., C. Agnese and F. D’Asaro, 2009. Estimation of solar radiation in Sicily by daily data maximum and minimum temperature. Italian $\mathrm{J}$. Agrometeorol., 14: 84-85.

Grillone, G., C. Agnese and F. D'Asaro, 2012. Estimation of daily solar radiation from measured air temperature extremes in the mid-Mediterranean area. J. Irrigat. Drainage Eng., 138: 939-947. DOI: 10.1061/(ASCE)IR.1943-4774.0000480

Grillone, G., G. Baiamonte and F. D'Asaro, 2014. Empirical determination of the average annual runoff coefficient in the Mediterranean area. Am. J. Applied $\quad$ Sci., $\quad$ 11: 89-95. DOI: 10.3844/ajassp.2014.89.95

Guerrieri, G., F. Pennacchi and T. Sediari, 1995. Istituzioni di Economia e Politica Agraria. 1st Edn., Edagricole, Bologna, Italy, ISBN-10: 882063953X, pp: 738.

Gunnarsson, C., R. Spörndly, H. Rosenqvist, A. De Toro and P.A. Hansson PA et al., 2009. A method of estimating timeliness costs in forage harvesting illustrated using harvesting systems in Sweden. Grass Forage Sci., 64: 276-291. DOI: 10.1111/j.1365-2494.2009.00693.x

Houssou, N., X. Diao, F. Cossar, S. Kolavalli and K. Jimah et al., 2013. Agricultural mechanization in Ghana: Is specialized agricultural mechanization service provision a viable business model. Am. J. Agric. $\quad$ Econ., 95: 1237-1244. DOI: 10.1093/ajae/aat026

Ibáñez, A.M., F. Martinelli, R.L. Reagan, S.L. Uratsu and M.A. Tinoco et al., 2014. Transcriptome and metabolome analysis of citrus fruit to elucidate puffing disorder. Plant Sci., 217-218: 87-98. DOI: 10.1016/j.plantsci.2013.12.003.

Intrieri, C. and S. Poni, 2000. Physiological response of winegrape to management practices for successful mechanization of quality vineyards. Acta Horticulturae, 526: 33-47.

ISTAT, 2012. 6th general agricultural census. ISTAT

ISTAT, 2014. Superfici e produzioni delle principali coltivazioni. ISTAT.

Kaan Kurtural, S., G. Dervishian and R.L. Wample, 2012. Mechanical canopy management reduces labor costs and maintains fruit composition in 'Cabernet sauvignon' grape production. Hort Technol., 22: 509-516.

Keskin, G., F.F. Tatlidil and I. Dellal, 2010. An analysis of tomato production cost and labor force productivity in Turkey. Bulgarian J. Agric. Sci., 16: 692-699.
Kostadinov, G., D. Ivanov and V. Peykov, 2008. Effect of technological and regional conditions on costs in wine grape production. Bulgarian J. Agric. Sci., 14: 509-516.

Landa, M., 2012. Analysis of operating cost variability in selected sectors of the Czech Republic for the period 2007-2010. Acta Univ. Agric. Silvic. Mendelianae Brunensis, 60: 165-174. DOI: 10.11118/actaun201260020165

Lanfranchi, M., C. Giannetto and A. Puglisi, 2014. A cost-benefits analysis for risk management in a biological farm. Applied Math. Sci., 8: 775-787.

Morris, J.R., 2007. Development and commercialization of a complete vineyard mechanization system. Hort Technol., 17: 411-420.

Othman, M.S.H. and Z. Manan, 2011. Cost, sales and profit structure of wild ornamental plant collection at Cameron Highlands. Malaysian Forester, 74: 103-110.

Pezzi, F., G. Balducci, E. Barca and C. Caprara, 2013. Effects of winter pruning on physical and mechanical properties of grapes. Acta Horticulturae, 978: 347-352.

Rahman, S.M. and J. Takeda, 2007. Measuring the costs of production based on sizes of farm operation: A study on rice farmers in Jessore District of Bangladesh. Am. J. Applied Sci., 4: 274-283. DOI: 10.3844/ajassp.2007.274.283.

Rodriguez, M.A., J.E. Ricart and P. Sanchez, 2002. Sustainable development and the sustainability of competitive advantage: A dynamic and sustainable view of the firm. Creativity Innov. Manage., 11: 135-146. DOI: 10.1111/1467-8691.00246

Rolshausen, P.E., J.R. Úrbez-Torres, S. Rooney-Latham and A. Eskalen et al., 2010. Evaluation of pruning wound susceptibility and protection against fungi associated with grapevine trunk diseases. Am. J. Enol. Viticulture, 61: 113-119.

Salami, P., H. Ahmadi and A. Keyhani, 2010. Estimating the Energy Indices and Profitability of Strawberry Production in Kamyaran Zone of Iran. Energy Res. J., 1: 32-35. DOI: 10.3844/erjsp.2010.32.35

Santeramo, F.G., J. Di Pasquale, F. Contò, S. Tudisca and F. Sgroi et al., 2012. Analyzing risk management in Mediterranean Countries: The Syrian perspective. New Medit, 11: 35-40.

Selvan, M.M., R. Manian, K. Kathirvel and K. Rangasamy K, 2012. Economics of basin-lister cum seeder for ln-situ moisture conservation in drylands of indian cotton fields. AMA, Agric. Mechaniz. Asia, Africa Latin Am., 43: 84-88. 
Smithyman, R.P., G.S. Howell and D.P. Miller, 1997. Influence of canopy configuration on vegetative development, yield and fruit composition of seyval blanc grapevines. Am. J. Enol. Viticulture, 48: 482491.

Tardaguila, J., J.A. Blanco, S. Poni and M.P. Diago, 2012. Mechanical yield regulation in winegrapes: Comparison of early defoliation and crop thinning. Aust. J. Grape Wine Res., 18: 344-352. DOI: $10.1111 / \mathrm{j} .1755-0238.2012 .00197 . \mathrm{x}$

Tudisca, S., F. Sgroi and R. Testa, 2011. Competitiveness and sustainability of extreme viticulture in Pantelleria Island. New Medit, 10: 57-64.

Tudisca, S., A.M. Di Trapani, F. Sgroi and R. Testa, 2013a. The cost advantage of Sicilian wine farms. Am. J. Applied Sci., 10: 1529-1536. DOI: 10.3844/ajassp.2013.1529.1536

Tudisca, S., A.M. Di Trapani, F. Sgroi, R. Testa and R. Squatrito et al., 2013b. Economic analysis of PV systems on buildings in Sicilian farms. Renewable and Sustainable Energy Rev., 28: 691-701. DOI: 10.1016/j.rser.2013.08.035
Tudisca, S., A.M. Di Trapani, F. Sgroi and R. Testa, 2013c. Marketing Strategies for Mediterranean Wineries Competitiveness. The Case of Pantelleria. Quality-Access Success, 14: 101-106.

Tudisca, S., A.M. Di Trapani, E. Donia, F. Sgroi and R. Testa et al., 2014a. Entrepreneurial strategies of Etna wine farms. Inter. J. Entrepreneurship Small Bus., 21:

155 164.DOI: 10.1504/IJESB.2014.059470

Tudisca, S., A.M. Di Trapani, F. Sgroi and R. Testa, 2014b. Economic evaluation of PDO introduction in Sicilian orange farms. Quality-Access Success, 14: 99-103.

Tudisca, S., A.M. Di Trapani, F. Sgroi and R. Testa, 2014c. Organic farming and economic sustainability: The case of Sicilian durum wheat. Quality-Access Success, 15: 93-96.

Tudisca, S., A.M. Di Trapani, F. Sgroi, R. Testa and G. Giamporcaro et al., 2014d. Role of alternative food networks in sicilian farms. Inter. J. Entrepreneurship Small Bus., 22: 50-63. DOI: 10.1504/IJESB.2014.062130 